\title{
THE PROVISION OF SERVICES OF GENERAL INTEREST IN EUROPE: REGIONAL INDICES AND TYPES EXPLAINED BY SOCIO-ECONOMIC AND TERRITORIAL CONDITIONS 1
}

\author{
ALOIS HUMER \\ Department of Geography and Regional Research \\ University of Vienna \\ Universitaetsstrasse 7/5, 1200-Vienna, AUSTRIA \\ alois.humer@univie.ac.at \\ PEDRO PALMA \\ Centre for Geographical Studies \\ University of Lisbon \\ Alameda da Universidade, 1600-214, Lisbon, PORTUGAL \\ p.palma@campus.ul.pt
}

\begin{abstract}
This paper analyses the provision of services of general interest (SGI) in European regions. The EU policy goals connected to SGI address fair access and support for social and territorial cohesion. A comprehensive view of SGI and, specifically, the different domains of Services of General Economic Interest and Social Services of General Interest enable us to discuss regional dependencies in respect of SGI provision in relation to various territorial, social and economic contexts. Significant patterns of SGI provision on two regional levels - European and sub-national - are detected, and socio-economic conditions are identified as the prime drivers.
\end{abstract}

Key words: services of general interest, drivers, Europe, ESPON, NUTS 2, index, typology, correlation

\section{THE NOTION OF SERVICES OF GENERAL INTEREST}

Services of general interest (SGI) represent a framing term in EU policies for a multitude of different kinds of services and infrastructures that represent a vital requirement for both individual citizens and businesses. The question of SGI is a complex issue in the EU policies as a number of special features are ascribed to these vital services with regards to (1) competition rules and single market objectives; and (2) social and human rights. Additionally, SGI is a highly normative political term

1 This paper is part of the applied research project Indicators and Perspectives for Services of General Interest in Territorial Cohesion and Development (SeGI), led by the Royal Institute of Technology (KTH), Sweden. It has been financed by the ESPON 2013 Programme and this financial support is gratefully acknowledged. Texts, maps and conclusions stemming from research projects under the ESPON programme presented in this report do not necessarily reflect the opinion of the ESPON Monitoring Committee. (C) ESPON, 2013. 
with the definition of what is a service of general interest being left to the individual Member States; even though the EU often pro-actively takes the initiative in this policy field ${ }^{2}$. Thus, the definition of which service is "of general interest" is neither homogenous nor applicable across Europe.

This paper's focus lies on the substantive dimension of SGI in European regions, and less on definitional concerns. Therefore, the term "services of general interest" is understood broadly. In a first step towards the de-aggregation of services of general interest, the two domains i.e. Services of General Economic Interest (SGEI) and Social Services of General Interest (SSGI) can be distinguished in accordance with their political-normative definition in the EU treaties and communications. In broad terms, SGEI contain two sub-domains, namely, technical infrastructures, such as energy, water, waste and transportation, and communicational infrastructures, like postal services, business support, ICT and telecoms. SSGI on the other hand contain four sub-domains: education, health and care services, labour market services, and social housing. Definition-wise, the paper follows the elaborations and findings of the project ESPON SeGI (see Rauhut et al., 2013) which constitutes the research arena for this contribution.

In this paper, a comprehensive view of SGI provision across European regions is taken. The area of research comprises the 286 NUTS 2 regions of EU 27 plus the following three EFTA states: Iceland, Norway and Switzerland. The heterogeneity of various 'services' associated with SGI has already been alluded to above, primarily in relation to the division of SGI into two different organisational logics, requiring different means of production and supply, and thus manifesting themselves differently in their prevailing territorial, social and economic contexts. On the basis of this thematic heterogeneity, the first research question thus emerges, namely, how much differentiation can be seen in the performance of European regions in terms of SGI provision? A second, follow up, research question then seeks to determine an explanation for these regional differences by asking to what extent socio-economic and territorial conditions correlate with the different performance in SGI provision in the European regions?

\section{POLITICAL, ECONOMIC AND TERRITORIAL CONTEXTS}

The provision of services of general interest is exposed to several drivers and megatrends in political, social, economic and territorial terms. As elaborated above, the term itself derives from EU policy, and thus it is clearly political-normative in nature. It is, moreover, also a term of high political relevance. The major aim formulated by the European Union in this field is fair access to SGI for all citizens, irrespective of where they live. The EU White Paper on SGI states that "Citizens [...] rightly expect to have access to affordable high-quality services of general interest throughout the European Union. For the citizens of the European Union this access is an essential component of European citizenship and necessary in order to allow them to fully enjoy their fundamental rights" CEC, 2004: Article 2.1). The above-mentioned territorial aspect of this policy aim is made more explicit when it comes to territorial cohesion, as formulated in the Interim Territorial Cohesion Report of 2004. "Territorial cohesion includes fair access for citizens and economic operators to services of general economic interest (SGEI), irrespective of the territory to which they belong" (DG REGIO 2004: 3). "The [EU] Treaty explicitly recognizes the important role played by the services of general interest in

\footnotetext{
2 See the respective Articles in the founding treaty of the EU (EEC 1957: art. 90, par. 2), the charter of fundamental rights of the EU (EC 2000: art. 36), the Green Paper (CEC, 2003: par. 16) and the White Paper (CEC, 2004) on SGI of the European Commission and an EC communication on SSGI (CEC, 2007).
} 
the promotion of social and territorial cohesion. The political importance of these services is obvious, as they represent an essential element of the European model of society." (DG REGIO 2004: 51). This gives the provision of SGI a clear social and territorial dimension.

The provision of SGI is further framed by socio-economic circumstances, and is exposed to public, that is to say, governmental forms of organisation and finance. This of course is not to say that the public sector is, or can be, the only provider of such services. The situation is much more complex than that. Private - commercial and familial - engagement is an inherent part of SGI provision in European states and regions, not least due to the competition rules and single market regulations that account in particular for services of general economic interest. Kaul and Mendoza highlight the linkage between the public and private spheres in service and goods provision, noting that" [...]'private' can no longer simply be equated with markets, and 'public' with states. Both contribute, among others, to the public and private domains. Moreover, the properties of goods can change from being public or private and from private to public" (Kaul and Mendoza, 2003: 80). Especially in times of limited public financial resources, new and alternative forms of financing - integrating the commercial private sphere - become mainstream models. Therefore, regional socio-economic conditions and potentials are of importance for the successful provision of SGI.

The type of territory of a region is also a determining factor in the provision of SGI. According to the European Commission's Directorate General for Regional Policy, a particular type of territory is classified, primarily, by means of population densities and spatial features (see CEC 2010 and Dijkstra\& Ruiz, 2010). The efficient delivery of SGI is therefore generally easier in regions with high population densities and well-connected settlement patterns. Access to SGI is however a particular challenge in less favoured territories, like border regions, islands or mountainous regions. Nevertheless, for these generally less populated areas, the principle policy aims of fair access and universal provision in respect of SGI as well as fair living conditions under the umbrella of territorial cohesion still have to be applied if the above-mentioned policy aims are to be fulfilled across the European Union as a whole. It thus becomes a spatio-demographic issue when demographic megatrends like fertility rates below the reproduction rate and societal ageing through to rising life expectancy are clearly very different across Europe's regions (see De Beer et al., 2010) and thus could, indirectly, also have an impact on the provision of SGI.

In what follows, individual SGI indicators referring to the different domains and sub-domains of SGI are combined and analysed on level of NUTS 2 regions for 30 European states with the aim of producing two kinds of results. First, the overall SGI provision of the different European regions is analysed and second, these results are correlated with contextual drivers in order to explain the emergent territorial patterns in a more in-depth manner.

\section{DATA AND METHOD}

This study operates on a quantitative level. ${ }^{3}$ Useful statistical indicators that represent the situation, in output or input terms, in respect of different SGI have been identified. The selection of indicators is, however, limited by the pre-requisites of a chosen method. Only indicators that are available on the NUTS 2 level, for the whole area of research (EU $27+3)$, and in an up-to-date version (latest year 2008) have been processed. Concerning the various sub-domains of SGI, only those with at least three

\footnotetext{
3 If not differently stated, the source of the data used in this analysis is EUROSTAT, partly taken from the ESPON database. The remaining gaps were filled with data from the respective national statistical offices.
} 
SGI indicators are represented in the study; these are education and health care SGI, from of the SSGI domain, and a combination of technical and communicational sub-domains from the SGEI domain.

Figure 1 shows the logic of defining the domains of SGI. The indices of the sub-domains of educational SGI and healthcare SGI in this study represent the SSGI domain. These two indices were subsequently entered into an aggregated SSGI index. The SGEI domain is fed by a combination of indicators from both sub-domains; technical and communicational infrastructures. In a final aggregation step, the indices of both SSGI and SGEI are combined to form an overall regional index of SGI, with fair weight given to each domain. By crossing the indices of SSGI and SGEI, a fourquarter-typology of SGI provision can be calculated.

Table 1. Background SGI indicators for regional indices

\begin{tabular}{|c|c|c|}
\hline SGI Indices & Representative fields & Background SGI indicators on the NUTS 2 level \\
\hline \multirow{4}{*}{$\begin{array}{l}\text { Economic } \\
\text { SGI } \\
(\mathrm{SGEI})\end{array}$} & $\begin{array}{l}\text { High ranked transport } \\
\text { infrastructure }\end{array}$ & Length of motorways in km per 1,000 km2(2009) \\
\hline & $\begin{array}{l}\text { High quality ICT } \\
\text { infrastructure }\end{array}$ & Percentage of households with access to broadband (2010) \\
\hline & $\begin{array}{l}\text { Vital business } \\
\text { surrounding }\end{array}$ & Persons employed per 100,000 inh. in PR and consultancy (2009) \\
\hline & Public finance & National public expenditures on economic affairs per inh. (2009) \\
\hline \multirow{4}{*}{$\begin{array}{l}\text { Educational } \\
\text { SGI }\end{array}$} & $\begin{array}{l}\text { Attainment of lower } \\
\text { education }\end{array}$ & $\begin{array}{l}\text { Students in pre-primary edu. per } 100 \text { inh. of resp. age-group } \\
(2009)\end{array}$ \\
\hline & $\begin{array}{l}\text { Attainment of higher } \\
\text { education }\end{array}$ & $\begin{array}{l}\text { Students in upper secondary edu. per } 100 \text { inh. of resp. age-group } \\
(2009)\end{array}$ \\
\hline & $\begin{array}{l}\text { Attainment of tertiary } \\
\text { education }\end{array}$ & Students in tertiary edu. per 100 inh. of resp. age-group (2009) \\
\hline & Public finance & National public expenditures on education per inh. (2009) \\
\hline \multirow{4}{*}{$\begin{array}{l}\text { Health care } \\
\text { SGI }\end{array}$} & $\begin{array}{l}\text { Availability of main } \\
\text { health care }\end{array}$ & Available hospital beds per 100,000 inh. (2008) \\
\hline & $\begin{array}{l}\text { Availability of primary } \\
\text { health care }\end{array}$ & Physician and doctors per 100,000 inh. (2008) \\
\hline & $\begin{array}{l}\text { Availability of additional } \\
\text { care }\end{array}$ & Professional nurses and midwives per 100,000 inh. (2008) \\
\hline & Public finance & National public expenditures on healthcare per inh. (2009) \\
\hline \multirow{2}{*}{$\begin{array}{l}\text { Social SGI } \\
\text { (SSGI) } \\
\text { aggregated }\end{array}$} & Educational SGI & Additive Z-scores of 4 educational SGI indicators (half weighted) \\
\hline & Health care SGI & Additive Z-scores of 4 healthcare SGI indicators (half weighted) \\
\hline \multirow{2}{*}{$\begin{array}{l}\text { SGI } \\
\text { aggregated }\end{array}$} & Economic SGI (SGEI) & Additive Z-scores of 4 economic SGI indicators \\
\hline & Social SGI (SSGI) & Additive Z-scores of education and healthcare SGI indices \\
\hline
\end{tabular}

Data sources: EUROSTAT\& ESPON database. 


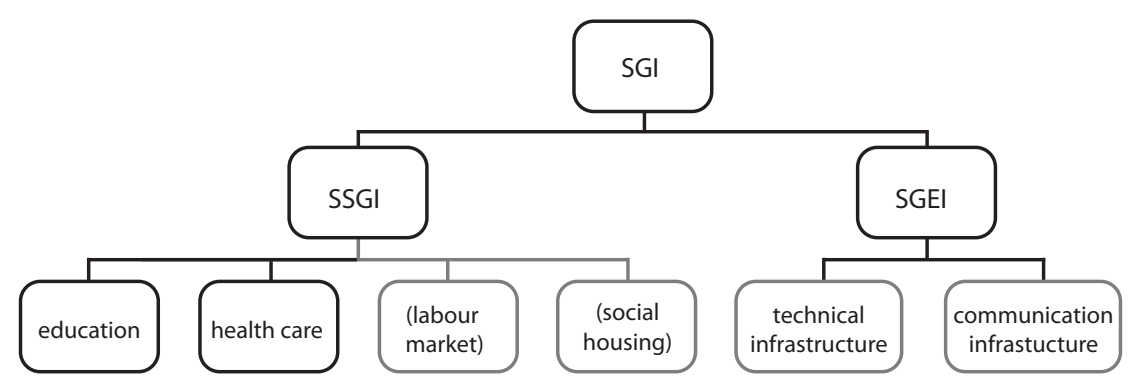

Figure 1. SGI (sub-)domains referred to in the index and typology building

In order to make these different indicators - like doctors per inhabitants or the percentage of households with access to broadband internet etc. - comparable and operational in a multivariate statistical analysis, each indicator first has to be standardised by means of undergoing a Z-transformation on its own. A Z-transformation changes the original value of a respective indicator into a relative value of standardised, statistical distance. First, the mean value of the indicator is calculated. In a second step, each value's distance to the mean is expressed in standard deviation. If a region's value for one indicator is exactly the mean value of the whole indicator, this region's value is Z-transformed into zero - of course this is a theoretical case when operating with metric data. So the values of the regions for a respective indicator turn into positive and negative values, according to their distance - expressed by standard-deviation-from the mean value. As a result, every region receives a negative or positive value that indicates the distance to the European mean.

After these preparatory modifications of the data, indices of additive scores of these single Z-transformed indicators can be formed. This procedure is done for the three indices of economic, educational and healthcare SGI. The construction of the two aggregated indices follows this method, which is different only in the sense that the background indicators used are the previously calculated indices of the sub-domains, and no longer single indicators. Both indices, on educational and healthcare SGI, are weighted only half before being added to a grand aggregated regional index of SSGI. This is an important step as it allows the equal inclusion of the SSGI and SGEI indices into the final index of SGI. Otherwise the eight Z-transformed indicators from the SSGI side would be overrepresented in relation to the four Z-transformed indicators from the SGEI domain. Doing so, there is no subjective weighting included but both sides, the SSGI index and the SGEI index are represented with the same weight, even though they have been formed through a different amount of indicators.

In order to set the SGI indices of European regions into a clear socio-economic and territorial context, bi variate PEARSON correlations and multivariate regression analyses are calculated for regional indicators representing the regions' condition. A PEARSON correlation coefficient ranges from -1 (negative correlation) to +1 (positive correlation) in extreme cases. A multivariate regression analysis has one dependent variable - in this case an SGI index - and two or more independent, explanatory, variables - in this case context indicators. The most important figures are $\mathrm{R}^{2}$ corr and BETA. $\mathrm{R}^{2}$ corr (from 0 to 1 ) tells us about the performance of a calculated analysis while BETA expresses the importance of each of the independent variables within the equation. ${ }^{4}$

\footnotetext{
${ }^{4}$ A detailed introduction to methods of standardisation, correlation and regression is provided by Backhaus et al. (2000).
} 
Table 2. National public expenditures on the relevant SGI (sub-)domains

\begin{tabular}{|c|c|c|c|}
\hline \multirow[b]{2}{*}{ EU 27 plus 3 EFTA } & \multicolumn{3}{|c|}{ Yearly national public expenditures in 2009 (in EUR per capita) } \\
\hline & Economic affairs & Educational system & Healthcare system \\
\hline Austria & 1791 & 1899 & 2718 \\
\hline Belgium & 1848 & 2009 & 2523 \\
\hline Bulgaria & 200 & 198 & 194 \\
\hline Cyprus & 782 & 1531 & 694 \\
\hline Czech Republic & 1012 & 654 & 1047 \\
\hline Denmark & 1321 & 3232 & 3553 \\
\hline Estonia & 537 & 731 & 579 \\
\hline Finland & 1624 & 2132 & 2571 \\
\hline France & 1031 & 1765 & 2369 \\
\hline Germany & 1130 & 1252 & 2126 \\
\hline Greece & 1138 & 841 & 1623 \\
\hline Hungary & 527 & 485 & 463 \\
\hline Iceland & 1637 & 2323 & 2265 \\
\hline Ireland & 2633 & 2197 & 3181 \\
\hline Italy & 1137 & 1173 & 1918 \\
\hline Latvia & 591 & 555 & 380 \\
\hline Lithuania & 317 & 543 & 442 \\
\hline Luxembourg & 3392 & 3824 & 3892 \\
\hline Malta & 692 & 775 & 779 \\
\hline Netherlands & 2162 & 2068 & 2845 \\
\hline Norway & 2473 & 3436 & 4299 \\
\hline Poland & 435 & 455 & 418 \\
\hline Portugal & 723 & 919 & 1167 \\
\hline Romania & 423 & 225 & 211 \\
\hline Slovakia & 606 & 503 & 905 \\
\hline Slovenia & 906 & 1136 & 1228 \\
\hline Spain & 1280 & 1155 & 1559 \\
\hline Sweden & 1474 & 2289 & 2327 \\
\hline Switzerland & 2035 & 2778 & 946 \\
\hline United Kingdom & 1120 & 1769 & 2142 \\
\hline
\end{tabular}

Data source: EUROSTAT: section COFOG, gov_a_exp.

The results, and a more detailed elaboration, of the five, in total, regional indices and their linkage with socio-economic and territorial context indicators will be reproduced in the following chapter. In what remains of this chapter an introduction will be given to the background SGI indicators used. While the first three background indicators of each sub-domain's index allow for a comprehensive expression of the situation in terms of economic, educational and healthcare SGI, the fourth indicator -on public expenditures- integrated into each of the three indices represents the inputs into and efforts made in a particular policy field of SGI (see Table 1, right column). This fiscal indicator ena- 
bles an important distinction to be drawn between countries and regions on the basis of government investment in the improvement and maintenance of the respective SGI sub-domains. The expenditure indicators are shown in Table 2.5

The entries for national public expenditures on economic affairs highlight Norway, Ireland and Luxembourg as having the highest values in terms of public investment - exceeding 2000 EUR per inhabitant - followed by Benelux, Switzerland, Austria and the Nordic states. In general, however, there is a significant discrepancy between the EU15 and the new EU Member States, with the latter group of states generally having lower values, down to ca. 200 EUR per inhabitant in Bulgaria. For expenditures on education the situation is not very different. Those spending most again include the Nordic countries, the Benelux countries, Switzerland and Ireland. Once again there is a clear gap between the EU15 and the new EU Member States. The total range is from ca. 3800 EUR per inhabitant in Luxembourg down to ca. 200 EUR per inhabitant in Bulgaria. As for investment in the healthcare system the level of government expenditure already provides a good indication of the lower levels of investment in the new EU Member States. The Nordic countries, Benelux countries, Ireland, France and Austria present highest values.

The three indicators of national public expenditures reveal a clear distinction between the EU15 and the new EU Member States with the former generally having higher levels of financial input into SGI. In general terms the Nordic and Benelux countries as well as Ireland, Austria and Switzerland come out on top across the board while the Baltic countries, Poland, Hungary, Romania and Bulgaria have least financial input. This type of indicator seems, at first sight, to bias the results of the indices but given the fact that significant investment in SGI should lead to generally better availability and performance, this input-indicator is important for the creation of regional indices and typologies of SGI provision. However, at this macro analysis level, it is neither possible to evaluate whether high public investments are economically viable in relation to public budgets as a whole - e.g. in the case of Ireland - nor whether the financial investments are really efficiently used. The fiscal indicator is one of four background indicators and therefore its impact influence is only $25 \%$ of the total. Given the importance of also including the investment-side of SGI into the calculations and, in addition, cognisant of the limitations in terms of data availability, the indicator is based on a per capita disaggregation of NUTS 0 data down to NUTS 2 data which unfortunately hinders the formulation of a more detailed distinction of NUTS 2 regions within each of the 30 states surveyed - for a gross European comparison however it can still serve as a valuable indicator.

The additional SGI indicators used in this analysis will be reviewed in the following section on regional indices and typologies. In what follows below, the regional indices of economic SGI as well as the indices for the sub-domains of educational and health care SGI will be discussed in detail. These three indices are later aggregated to grand indices; the logic of aggregation is illustrated in figure 1 above.

5 The indicators on government expenditures are given in Euro per capita. The more complex version including purchasing power standards has not been taken into account. First because the data later is de-aggregated to NUTS 2 level by means of standardisation by population figures and second because the further statistical operations anyway lead to a standardised, abstract version of data and the absolute figures become unimportant. A detailed metadata description of the expenditure indicators is provided by EUROSTAT, section "Classification of the functions of government (COFOG)", finance statistics "gov_a_exp". 


\section{REGIONAL INDEX OF ECONOMIC SGI (SGEI)}

The regional index on Services of General Economic Interest is based upon three SGI indicators on transportation, business support and communications. Highly ranked transport and high quality ICT infrastructures as well as a communicative business surrounding are taken into account to express the relative performance of European NUTS 2 regions with regards to SGEI. The chosen SGI are characterised as supporting the basic needs of businesses and enterprises and promoting sound market conditions in terms of production and delivery from the supply side while also meeting the necessary conditions in terms of demand from the user side. In short, they are of key importance in establishing and running a business and generally interacting in the market. In addition to the three indicators it is necessary to integrate a fourth indicator which then allows for the efforts taken by the national government in terms of SGEI. The indicator refers to the public finance, more specifically, national public expenditures in economic affairs, as introduced in the previous section (see also Table 2). The use of this input indicator allows an important distinction to be made between countries that present a similar situation in terms of SGEI indicators according to the investment level and the efforts made by the public authorities to improve SGEI.

On a broad European scale, the EU 15 Member States show quite a better performance on economic SGI while in the new EU Member States mostly only the capital regions are above European average. On a regional level, it is generally the metropolitan areas that score higher. Most countries show a pattern where the capital regions are ranked higher than other regions - most obviously in the geographical outer rim of the EU as in Finland, Sweden, Norway and the UK as well as in the Mediterranean countries like Spain, Portugal and Greece. In some cases (such as Berlin or Lisbon), there is even a gravity effect in terms of having the lowest national performance for the neighbouring regions to the capitals. The 'island' territorial type is below the European average since high connectivity infrastructures with a wide operating range, such as motorways, are delimited on these territories. The hypothesis that SGI for businesses 'follow' their customers is more likely in this respect than assuming a 'trailblazer' role for these SGI. This means that regions of high economic power also trigger and foster the enhancement of economic SGI.

\section{REGIONAL INDEX OF EDUCATIONAL SGI}

The regional index of educational SGI is built on the services' output which is represented by enrolment figures in the non-compulsory schooling of pre-primary, upper-secondary and tertiary education. While attainment rates for compulsory schooling would provide a predictable result, a focus on non-compulsory schooling allows for a better evaluation of educational SGI in terms of their acceptance and attractiveness.

Again, one indicator concerning public financing is introduced to take into account the role of public investments in the provision of educational SGI. Due to the non-homogenous definition of what is understood by the upper-secondary level, this indicator was allotted less weight in the statistical processing and was weighted at only 0.5 compared to the other three indicators. ${ }^{6}$

The overall picture shows that the best scores are recorded in the Nordic countries as well as Italy, France and Spain. On closer inspection, however, the picture is rather more heterogeneous. Some countries record very high enrolment in only one field - e.g. Romania, Hungary and Germany

\footnotetext{
${ }^{6}$ The half-weighting of the indicator on upper-secondary enrolment is a compromise between totally excluding the indicator - due to the above mentioned uncertainties of definition in each country - and the full application of the actually important indicator in terms of educational SGI.
} 
in pre-primary schooling, and Greece, Poland, Lithuania and Iceland - in tertiary enrolment. Capital regions are again favoured - generally because of their scores in tertiary enrolment - but the national heterogeneity is usually quite low in most states, which suggests that educational SGI are practically immune to territorial differences and are, generally speaking, rather evenly distributed. Even on European scale, only a moderate deviation from the overall average can be observed; i.e. there are only a few regions that are far below or far above the average.
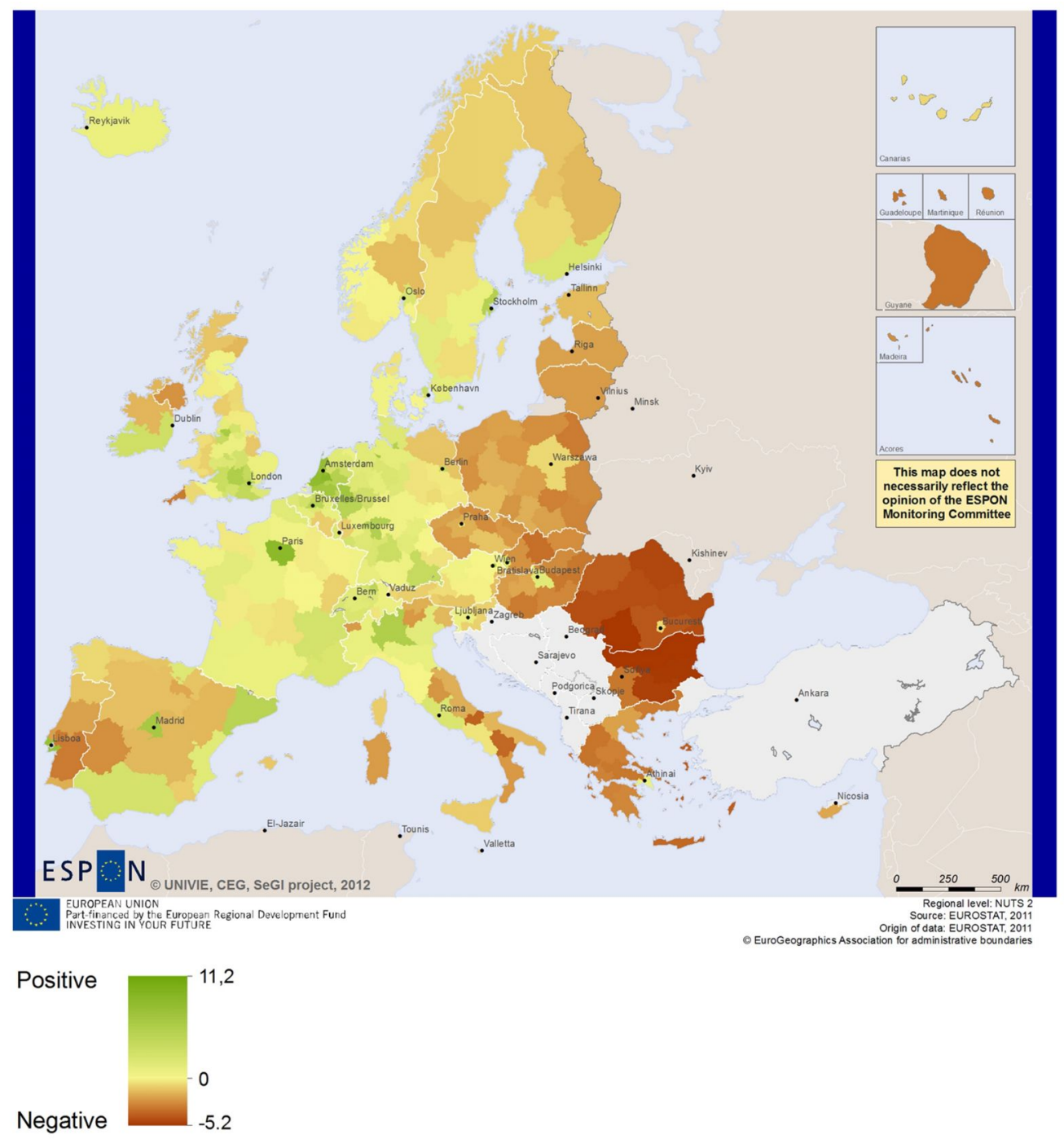

No data

Figure 2. Regional Index of Economic SGI (SGEI) 

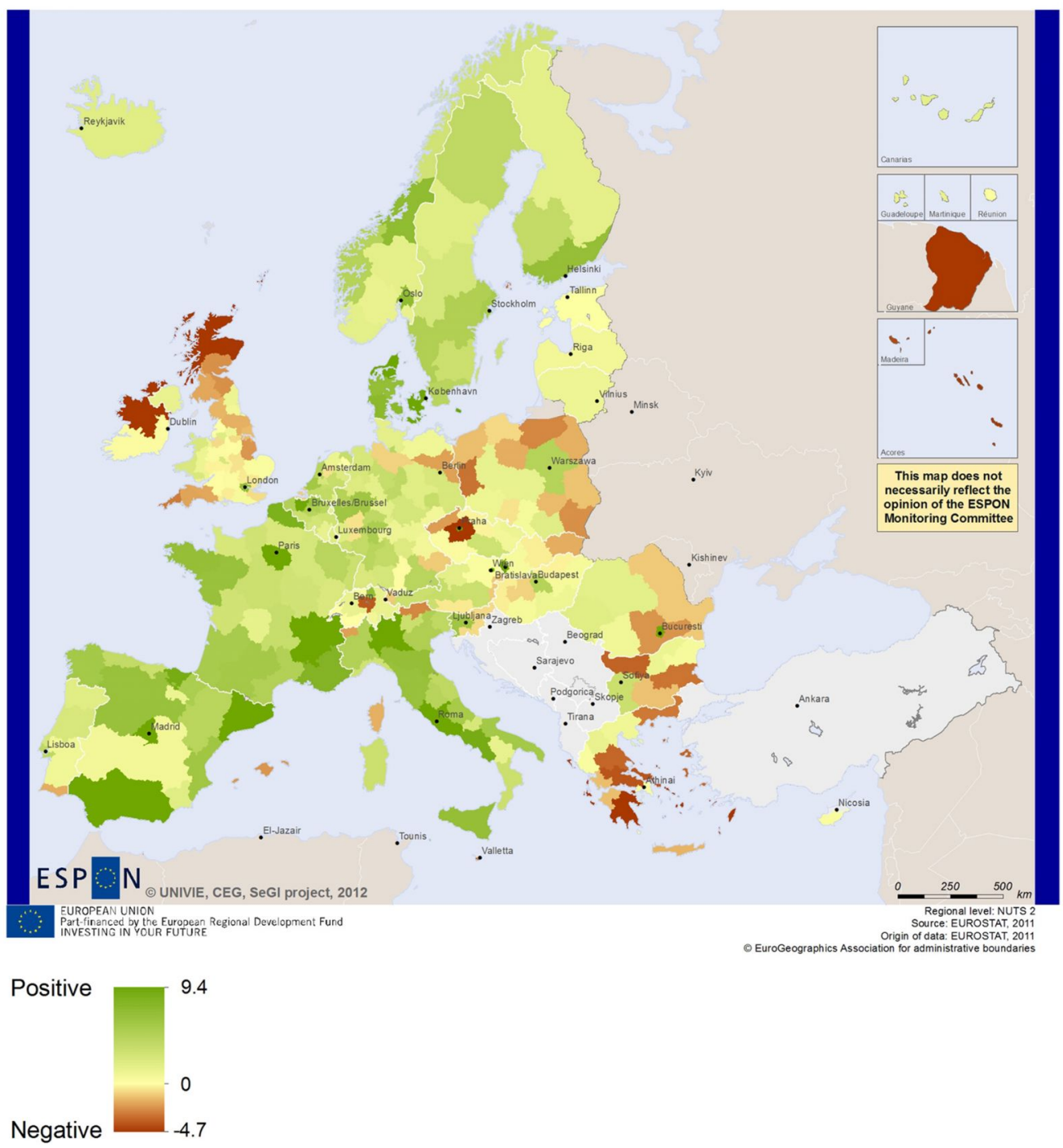

No data

Figure 3. Regional Index of Educational SGI

\section{REGIONAL INDEX OF HEALTHCARE SGI}

For the regional index on healthcare SGI, indicators representing the three most important questions in terms of the availability of health care are included in the analysis. This is a representation of primary health care (number of hospital beds), first aid (number of doctors), and care services (number of nurses) - each of them measured in relation to the number of inhabitants. To some extent, the different approaches utilised in regards to national health care policies produce different patterns in respect of these three indicators, the combined picture, however, allows for an international comparison. The number of hospital beds per inhabitants is quite a difficult indicator though and significantly depends on the state of development and focus on in- or out-patient 
treatment in the particular national healthcare system in question. As such, this indicator was once again weighted at 0.5 .

The Europe-wide analysis shows that the regions in Germany, northern Italy, southern France and Ireland have, in relative terms, the best level of health care availability. Additionally, some capital regions in South-Eastern Europe (Vienna, Bratislava, Budapest, Bucharest and Athens) are also worthy of mention here. The vast majority of regions of the new EU Member States are below or, in case of rural regions, far below the European average; same counts for Portugal and Spain. Within a national scope, most states witness a significant regional diversity within their NUTS 0 boundaries. The new EU Member States and Iberian countries have a high number of hospital beds per inhabitants, but fairly poor availability when it comes to first aid and care services.

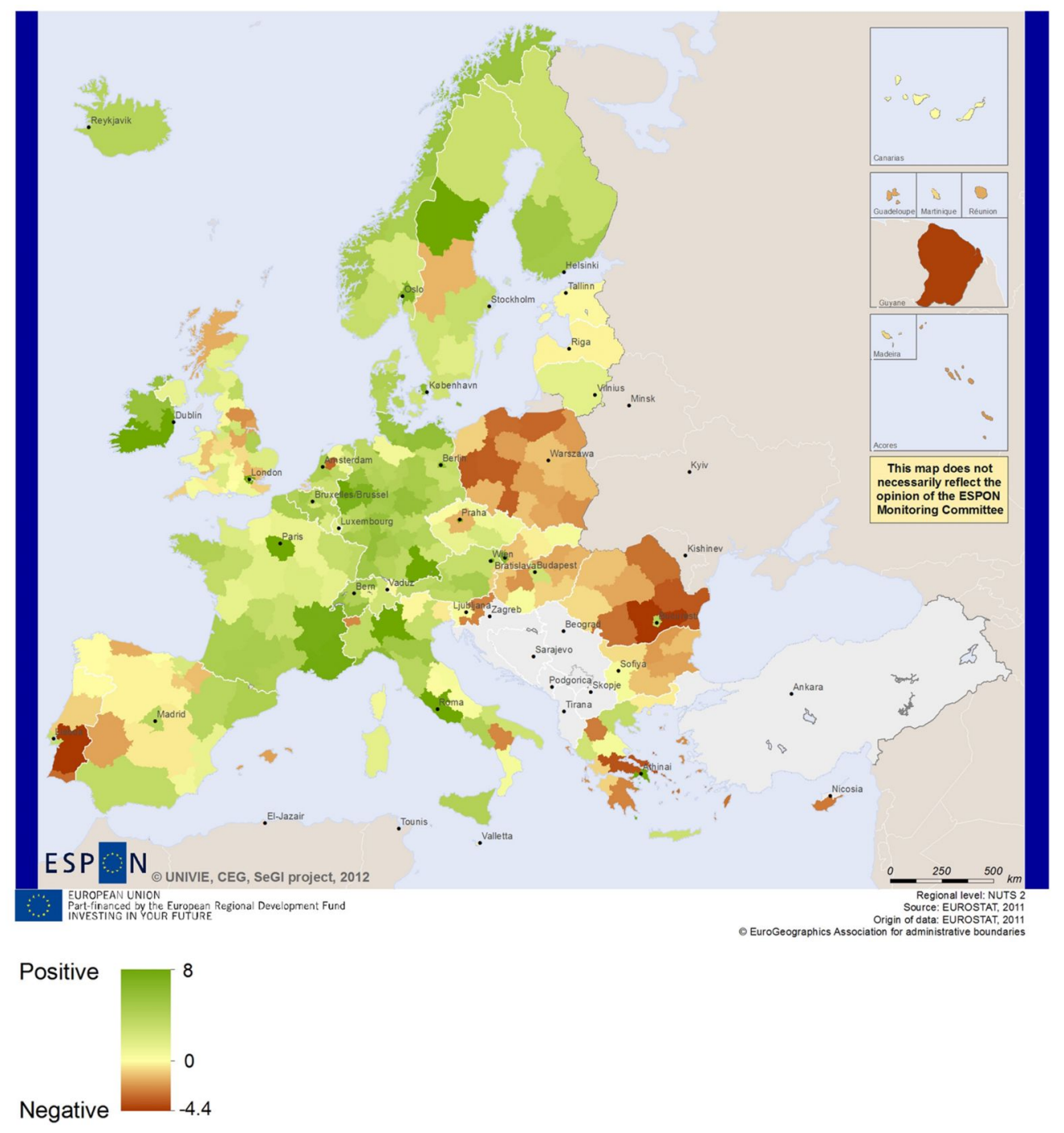



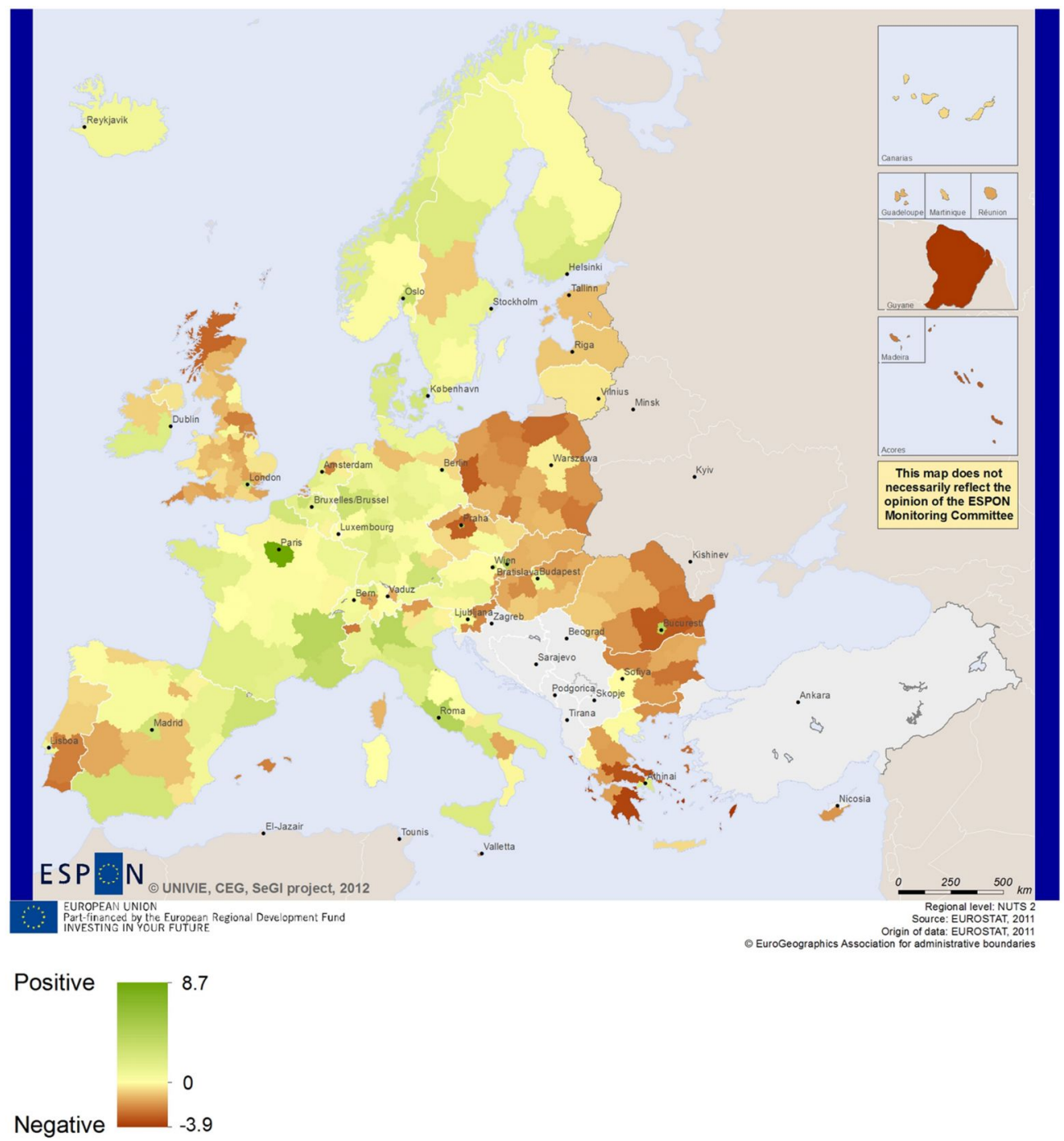

No data

Figure 5. Regional Index of Social SGI (SSGI)

Even when disregarding the financial input-indicators, a general picture of comprehensive SGI provision identifies the EU 15 regions as better equipped in Social Services of General Interest (education and health care), while not really surprisingly the "Pentagon" - regions and some additional capital regions clearly enjoy a better level of provision of Services of General Economic Interest. In the following, the two sub-domains of SSGI described above are connected through additive scores to a grand index of SSGI. In terms of the definition of SGI (see also Figure 1) this index then reaches the same hierarchy as the already calculated index of SGEI, and in a final step is then added to an aggregated index and typology of SGI in European regions. 


\section{AGGREGATED REGIONAL INDEX OF SOCIAL SGI (SSGI)}

The two indices on educational and health care SGI - used to construct an aggregated index of Social SGI - show a rather similar picture. The PEARSON correlation coefficient between those two indices is strongly positive with 0.610 . Still, the aggregated index values are partly eased the values for some regions which are relatively well-off in one sub-domain but below the European average in the other sub-domain.

The NUTS 2 regions of Ireland show the most heterogeneous picture, with educational SGI below the European average but health care SGI above the average. Otherwise, NUTS 2 regions generally tend to be fairly similar in both underlying social SGI indices. Taking this into account, the aggregated regional index of social SGI highlights a few regions in Italy, France and around national capital cities (like London, Copenhagen, Prague, Vienna, Bratislava and Bucharest) being far above the average. Regions far below the European average in a combined view on the domains of social SGI are mostly located in Eastern and Southern Europe. However, peripheral regions of e.g. Poland, Romania, Bulgaria, Greece and Portugal are joined by the coastal UK regions. A group of states in the North (excluding the Copenhagen area) and around the Baltic, as well as Germany and Ireland, are interesting because they do not register any extreme values - be they far below, or far above, the average. This means that these regions generally display rather average values in respect of SSGI provision. On the contrary, the UK, Italy, the Czech Republic and Romania contain regions displaying the full range between far below and far above the European average.

\section{AGGREGATED REGIONAL INDEX AND TYPOLOGY OF SGI}

In a final step, and on the basis of the aggregated regional index of social SGI and the index on economic SGI, a grand aggregated regional index and later a typology of SGI will now be presented. Respecting the limitations of such a multi-step aggregated and statistically transformed result, this last regional typology allows only for interpretation on a very general scale, and is meant to provide a general European picture only.

The regional index is again built by an additive score of the subordinated indices. Thanks to the half-weighting of educational and health care SGI when constructing the SSGI index, there is a fair share between both of the SGI domains' indices - even though the analysis is based on eight SSGI indicators but only four SGEI indicators.

If beforehand a rather smoothed picture of the European regional pattern of SGI was to be expected, due mainly to the broad range of indicators utilised, the actual result must, nevertheless, be seen in another light. A combined view of economic and social SGI shows a clear pattern and a wide range of NUTS 2 regions that are either 'far below' or 'far above' average in terms of SGI provision. Thus it is clear that the values for SGEI and SSGI reinforce each other, as they positively correlate with a PEARSON value of 0.619 .

This pattern disproportionately benefits urban and metropolitan regions - especially the capital regions of the EU 15 and other "Pentagon"-regions. Continental Western European regions are mostly above the European average while the regions of some East European states are nearly all far below the average; this pattern is particularly prevalent in the EU-external border regions.

The dot shading in Figure 6 illustrates the relative strength of SGEI and SSGI provision in each region. Irrespective of whether they are above or below the European average, the values of the SGEI index are predominantly higher in the UK regions and generally in the regions of North-West Europe - i.e. the so-called "Pentagon" - and in some additional capital regions; while SSGI provision makes 
a relatively better showing in peripheral regions - e.g. in the Baltic countries, Romania, Bulgaria, Iberia, southern Italy, Malta and Cyprus.

Figure 6 shows the results of the SSGI and SGEI indices in a non-metric expression. Every one of the 286 NUTS 2 regions is classified into one of the four sections relating to SSGI and SGEI index values. The benchmark for both indices is set at zero.

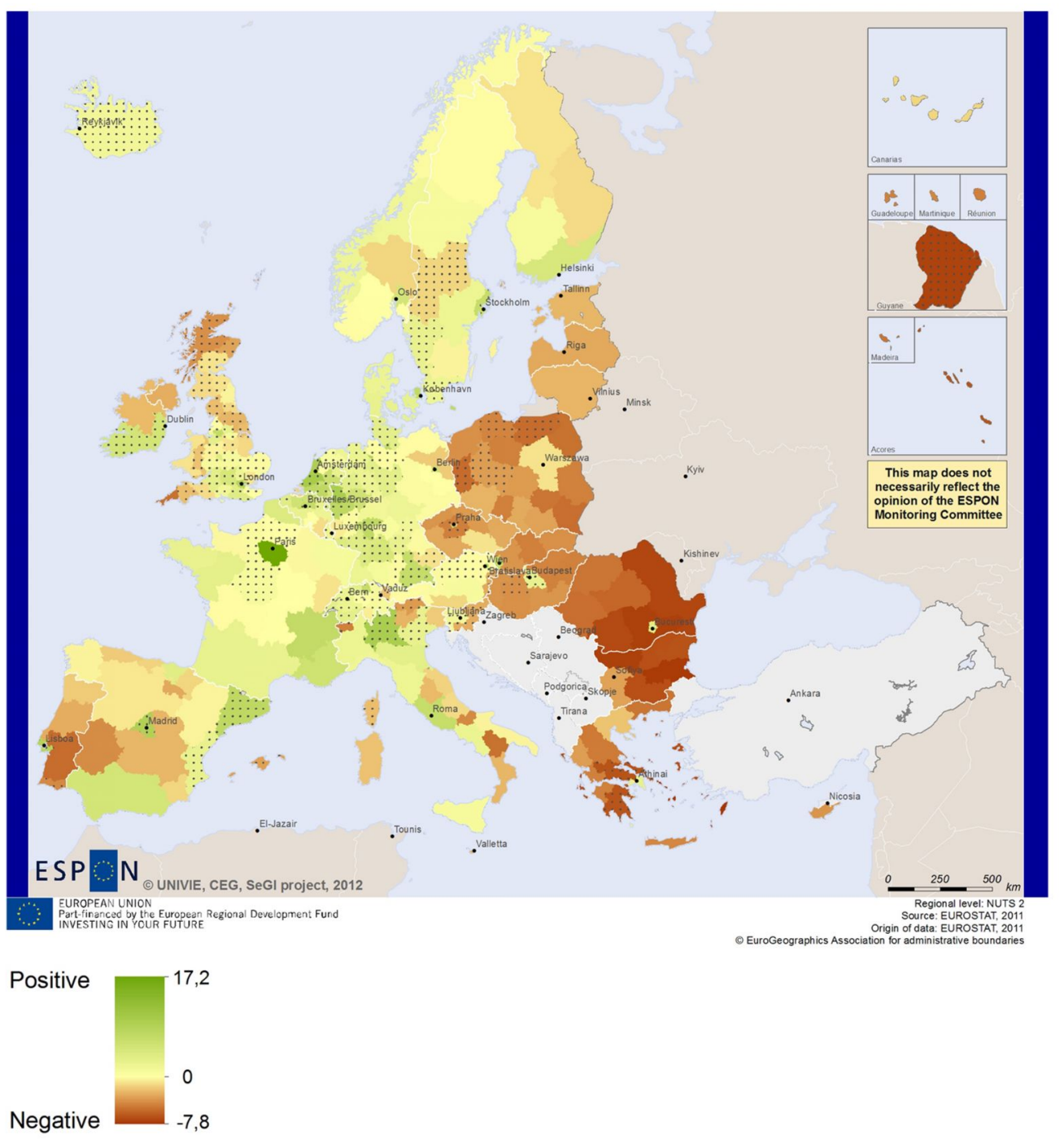

$::::$ SGEI index exceeds SSGI index

No data

Figure 6. Regional Index of Services of General Interest (SGI)

Western Germany, northern Italy and many French regions as well as the capital regions of the North are above average in both domains, while regions in the new EU Member States as well as peripheral regions of the British islands and of the Iberian Peninsula score worse in both sections, 
showing negative values in both domains. In respect of SGEI, positive value can at least be recorded for the predominantly sub-urban areas of Austria, Germany and the UK. On the contrary, as regards SSGI, positive values are generally to be found in more peripheral areas of the EU 15 Member States - such as the Nordic periphery, the Alpine regions, eastern Germany, northern Spain or southern Italy. This may indicate a strong national commitment to SSGI provision, particularly in the context of trying to counteract territorial disadvantages - which would be more difficult in the technical infrastructure related domain of SGEI.

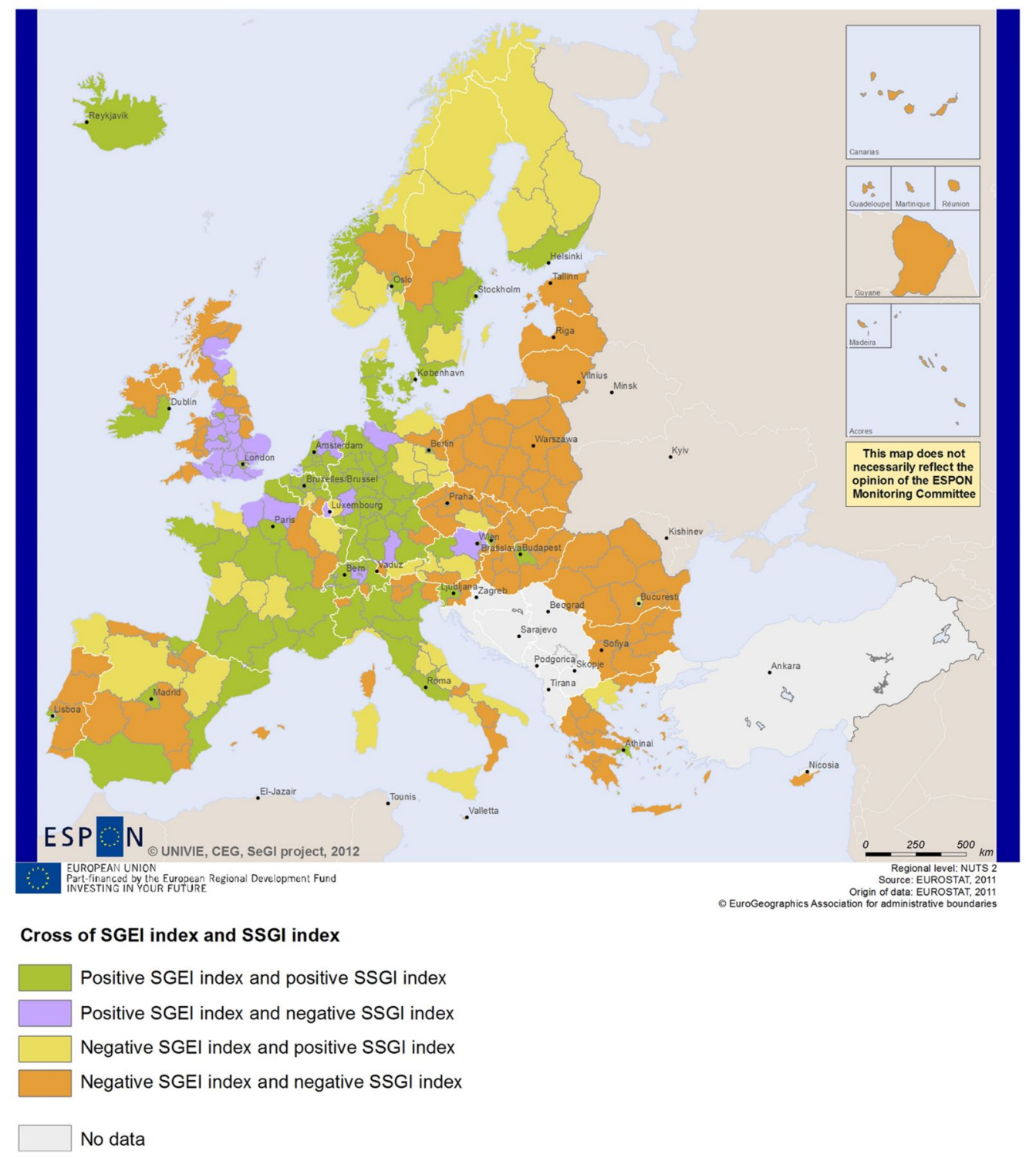

Figure 7. Regional Typology of Services of General Interest (SGI) 
Following the cartographic results in terms of the merging of the SSGI and SGEI indices, the scatter diagram in Figure 2 illustrates the above-mentioned positive correlation between the indices of two SGI domains. The dot cloud locates the regions predominantly in sector III - i.e. negative SSGI and negative SGEI index value - and in sector I - i.e. positive SSGI and positive SGEI index value.

Furthermore, Figure 8 adds territorial character to the analysis. The regions are displayed in two cross-groupings, Firstly, the EU 15 (plus 3 EFTA) versus the 12 new EU Member States, and secondly urban versus intermediate, versus rural regions. ${ }^{7}$ The macro picture of comparatively better SGI provision in the NUTS 2 regions of the EU 15 is overlaid by a detailed territorial picture of rather favoured urban regions, compared to rural regions. While most of rural regions in the EU 15 are placed on or around the European average, rural regions in the new EU Member States generally gravitate towards the bottom end of recorded scores for all the NUTS 2 regions.

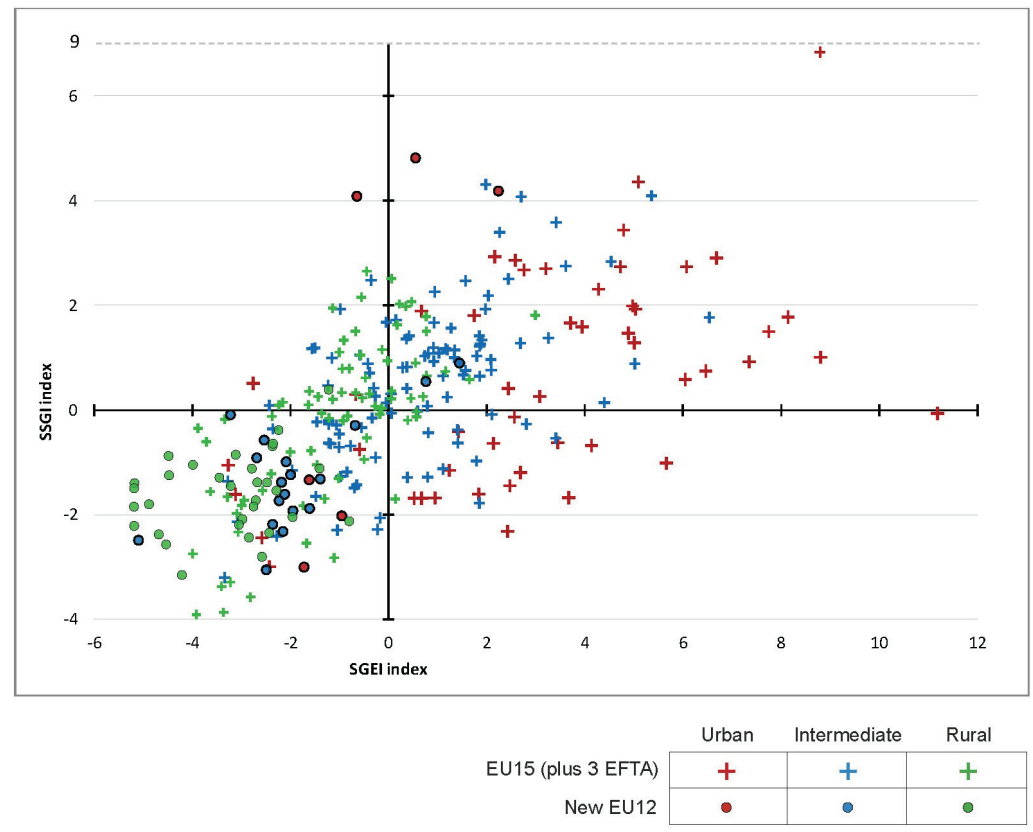

Figure 8: Correlation of regional SSGI and SGEI index values of NUTS 2 regions - by territorial character

The first research question can thus now be answered; the heterogeneity of SGI provision in Europe can be shown on a continental as well as a sub-national level. This multi-scale territorial picture, however, needs to be explained in rather greater depth. This next step was achieved by relating the resulting indices to important contextual indicators of territory, economy and socio-demographics. 


\section{REGIONAL SGI INDICES IN THEIR TERRITORIAL, SOCIAL AND ECONOMIC CONTEXTS}

Table 3 provides an overview of the context indicators and PEARSON correlation figures in respect of the main-domain typologies of SGEI, SSGI and SGI. A basic assumption lies behind each correlation.

The first two indicators represent the territorial context. The population density of a region should have a positive correlation with the presence of SGI. In contrast, regions with a high share of people living in rural areas should show a negative correlation, since SGI provision is supposed to be more difficult in rural areas.

The next two indicators refer, respectively, to the labour market and to economic potential. Here, the investment intensive and more business-related SGEI should have a positive correlation, this being the case for SSGI to a comparably lesser extent.

The final two indicators focus on citizens as users of SGI. Life quality, expressed here in terms of life expectancy at birth, should positively correlate with good SSGI provision. The yearly level of disposable household income per capita as a monetary indicator of well-being must be interpreted as a predictive variable in respect of SGI provision, as richer households are generally empowered to consume more, and better, SGI.

Table 3. Correlation values of regional indices with context indicators

\begin{tabular}{|l|c|c|c|c|c|c|}
\hline \multirow{2}{*}{$\begin{array}{c}\text { aggregated } \\
\text { regional } \\
\text { indices }\end{array}$} & \multicolumn{2}{|c|}{ Context indicators (2009-2010) } \\
\cline { 2 - 7 } & $\begin{array}{c}\text { territorial/ demographic } \\
\text { population } \\
\text { density }\end{array}$ & $\begin{array}{c}\text { macro-economic } \\
\text { share of rural } \\
\text { population }\end{array}$ & $\begin{array}{c}(\mathrm{d}) \\
\text { GDP } \text { per } \\
\text { capita }\end{array}$ & $\begin{array}{c}\text { (l) } \\
\text { rate of labour } \\
\text { participation }\end{array}$ & $\begin{array}{c}\text { (w) } \\
\text { life } \\
\text { expectancy }\end{array}$ & $\begin{array}{c}\text { socio-economic } \\
\text { household } \\
\text { income }\end{array}$ \\
\hline SGEI & 0.409 & -0.513 & 0.682 & 0.421 & 0.456 & 0.620 \\
\hline SSGI & 0.204 & -0.312 & 0.529 & 0.185 & 0.353 & 0.481 \\
\hline SGI & 0.364 & -0.480 & 0.688 & 0.364 & 0.459 & 0.625 \\
\hline
\end{tabular}

Data sources: (d), (e), (1), (w), (s): EUROSTAT // (t): aggregated onto NUTS 2 level after CEC 2010

(d) inhabitants per $\mathrm{km}^{2}, 2009$

(t) share of population living in predominantly rural NUTS 3 regions in \%, 2010

(e) GDP in $€$ per capita, $2009 / /$ (l) labour participation rate in \%, 2010

(w) life expectancy at birth in years, 2009

(s) average disposable household income in $€$ per capita and year, 2009

As described in the method chapter, a PEARSON correlation value ranges from -1 to 1 in extreme cases. In a social science context, values below -0.4 and above 0.4 may be regarded as being of explanatory value while those below -0.6 and above 0.6 may be regarded as being of strong explanatory value.

In this respect, population density seems to be a less important contextual indicator than initially supposed. The index of SGEI provision correlates positively at 0.409 to population density while there is less of a connection between SSGI provision and population density. This may mirror the character of SGEI, as opposed to that of SSGI, in a way that the provision of the former generally requires a high critical mass of users while the outreach is also higher compared to SSGI. Regions with a high share of rural population - which is the second contextual indicator - correlate negatively to SGI provision, which holds true particularly for SGEI that require the aforementioned higher critical mass. This result is in line with the first context indicator. Another reason for the relatively lower correlation 
values between the SSGI index and both territorial and demographic indicators may be the applied scale of NUTS 2 level which is a quite high aggregation when analysing rather small-scaled services, like doctors and hospitals as well as population densities.

The indicator of GDP per capita brings forward the strongest positive correlation with SGEI, SSGI and the overall SGI index. Given the high value of the PEARSON correlation, it is tempting to propose a simplification such as, "High SGI provision comes hand in hand with high financial means". Undoubtedly, the economic prosperity level of a given region is strongly positively correlated with the SGI provision in this region. The contextual indicator of labour participation provides good evidence for the pre-defined orientation and purpose of SGEI and SSGI. While SGEI are meant to create a vital labour environment - represented in a positive correlation of 0.421 - SSGI are provided rather independently of employment factors focusing, more on benefiting society as a whole.

Following this line of argumentation, it is striking that the socio-demographic context indicator of life expectancy is actually more strongly correlated with SGEI than with SSGI. According to the statistical results, it is, in the main, the total mix of SGI provision that best contributes to longer life expectancy - referring to a correlation value of 0.459 . The socio-economic context indicator of disposable household income per capita confirms the argument in respect of capital-related SGI provision from the macro level - see correlation with GDP - also on the micro/individual level. Regions with households which have high potential expenditure levels are generally well situated in terms of SSGI and especially SGEI - the latter being subsidised less in the EU Member States due to competition rules.

According to Table 2 and the elaboration above, the territorial indicator of share of rural population $(\mathrm{t})$, the macro-economic indicator of GDP per capita (e), and the socio-economic indicator of disposable household income (s) reach the most significant correlation values with the grand aggregated regional index of SGI. While bivariate correlation can only produce a non-directed relation, a multivariate regression analysis allows for the identification of causalities and enables us to plot the relative importance of several explanatory variables. In this case, the SGI index is the dependent variable that needs to be explained by the independent variables $\mathrm{t}$, e and $\mathrm{s}$. The regression analysis as a whole results in a satisfactory $\mathrm{R}^{2}$ corr of 0.562 on a level of significance of $99 \%$. The independent variables are, however, of a quite different explanatory value - BETA $\mathrm{e}=0.45$ and $\mathrm{t}=-0.30$ and $\mathrm{s}=0.18$. Consequently, the socio-economic variable is not able to provide an additional explanatory value to that already provided by the macro-economic and territorial variables. Since e and s show an autocorrelation of PEARSON 0.81, the variable $\mathrm{s}$ is taken out of the equation because the variable $\mathrm{e}$ can assume the duties in respect of the explanatory value for both the macro- and the socio-economic indicators. This leads to the final regression of SGI, which remains the dependent variable with GDP per capita and share of rural population, as the two independent, explanatory variables. The $\mathrm{R}^{2}$ corr is still reasonably high with an $\mathrm{R}^{2}$ korr of 0.553 on a level of significance of $99 \%$. The BETA values show that the macro-economic indicator e is, in relative terms, much more important for explaining the dependent variable $(0.60)$ than the territorial indicator $t(0.30)$.

Both the correlation and regression analyses can thus be seen as helping to explain the regionally heterogeneous level of SGI provision in European regions. The regional macro- and socio economic conditions are primarily linked to SGI provision. Moreover, territorial patterns, particularly in terms of settlement structures, do have an impact on SGI provision. 


\section{CONCLUSION}

This comprehensive review of SGI, including its various domains and sub-domains, has to some extent confirmed the currently existing heterogeneous nature of the regional distribution of SGI but has also - taking the results of the five regional indices together - revealed a more diversified territorial picture of the European territory that brings the EU 15 urban areas and regions into a comparably better light. Referring to the European average, it is generally the same kinds of regions that perform better in terms of SGI provision, in both of the sub-domains - SSGI and SGEI - since both of these indices correlate with each other. The fairly strong correlations revealed between the aggregated regional indices and the contextual indicators explain the drivers behind this result. SGI provision generally relates to the demographic and territorial structure of a region, but first and foremost to the socio-economic potentials of a region on the macro level - i.e. regional GDP - as well as the micro level - i.e. household income. In causal relation, the economic situation must be seen as the primary driver, and the SGI provision as the consequence of it.

This conclusion provides two final thoughts as we turn back to the political sphere. (1) Thinking of possible policy interventions, the creation of prosperity generating economic development is a field of action where regional policies can help to promote, albeit indirectly, better SGI provision levels. While this is undoubtedly a challenging task, it is more realistic to expect intervention in this area to have positive consequences than to expect significant change to occur in respect of the other main drivers, namely, demography and territory. (2) Accounting for the reality of SGI provision, the continuing likelihood - in a medium term - of severely constrained public budgets raises the need for even greater efforts to be made to identify more efficient forms of SGI provision as well as more co-operative forms of organisation between public and commercial, as well as familial, private spheres.

Editors' note:

Unless otherwise stated, the sources of tables and figures are the author(s), on the basis of their own research.

\section{REFERENCES}

Backhaus K., Erichson B., Plinke W., Weiber R., 2000. Multivariate Analysemethoden. Eine anwendungsorientierte Einführung. Berlin-Heidelberg-New York: Springer, $661 \mathrm{pp}$.

CEC, 2003. Green Paper on Services of General Interest. COM (2003) 270 final.

CEC, 2004. White Paper on Services of General Interest. COM (2004) 374 final.

CEC, 2007. Services of general interest, including social services of general interest: a new European commitment. COM (2007) 725 final.

CEC, 2010. Fifth report on economic, social and territorial cohesion. COM(2010) 642 final.

De Beer J., Van der Gaag N., Van der Erf R., Bauer R., Fassmann H., Kupiszewska D., Kupiszewski M., Rees P., Boden P., Dennett A., Jasinska M., Stillwell J., Wohland P., De Jong A., Ter Veer A. Roto J., Van Well L., Heins F., Bonifazi C., Gesano G. (eds.), 2010. DEMIFER - Demographic and migratory flows affecting European regions and cities. Final Report ESPON Applied Research Project 2013/1/3, Luxembourg: ESPON.

DG REGIO, 2004. Interim Territorial Cohesion Report. Luxembourg: European Communities. 
Dijkstra L., Ruiz V., 2010. Refinement of the OECD regional typology: Economic Performance of Remote Rural Regions. DG Regio \& OECD, http://www.oecd.org/dataoecd/41/56/45511797.pdf [15 July 2013].

EEC, 1957. Treaty Establishing the European Economic Community (Treaty of Rome). European Economic Community: Rome.

EC, 2000. Charter of Fundamental Rights of the European Union. Official Journal of the European Communities 2000/C 364/01.

ESPON Database, http://database.espon.eu [15 July 2013].

EUROSTAT, http://epp.eurostat.ec.europa.eu [15 July 2013].

Kaul I., Mendoza R.U., 2003. Advancing the Concept of Public Goods. [in:] I. Kaul, P. Conceicao, K. Le Goulven, R.U. Mendoza (eds.), Providing Global Public Goods - Managing Globalization, New York: UNDP, pp. 78-111.

Rauhut D., Smith C., Humer A., Ludlow D., Borges L. (eds.), 2013. SeGI - Indicators and perspectives for services of general interest in territorial cohesion and development. Final Report ESPON Applied Research Project 2013/1/16. Luxembourg: ESPON. 